Neurotrophins and their relevance to neurologic disease are reviewed by Kernie SG, Parada LF (Arch Neurol May 2000;57:654-657). Neurotrophin therapy has potential in diseases of the peripheral nervous system especially because its function has been studied in peripheral sensory ganglia. Trials of subcutaneous injections of nerve growth factor (NGF), the prototypical neurotrophin, in diabetic polyneuropathy have shown promising results.

\title{
RETT SYNDROME
}

\section{MECP2 MUTATIONS AND RETT SYNDROME PHENOTYPES}

Seventy-one sporadic and 7 familial Rett syndrome (RTT) patients were screened for MECP2 mutations by direct sequencing and the pattern of $\mathrm{X}$ chromosome inactivation $(\mathrm{XCI})$ was determined in 39 RTT patients at the Baylor College of Medicine, Houston, TX. Twenty-three different disease-causing MECP2 mutations were identified in 54 of 71 (76\%) sporadic and in 2 of 7 (29\%) familial cases. Thirty-one of 34 patients $(91 \%)$ with classic RTT had random XCI. Nonrandom XCI was associated with milder phenotypes. RTT is caused by a partial loss of MeCP2 function. (Amir RE, van den Veyver IB, Schultz R et al. Influence of mutation type and X chromosome inactivation on Rett syndrome phenotypes. Ann Neurol May 2000;47:670-679). (Respond: Dr Huda Y Zoghbi, Howard Hughes Medical Institute, Baylor College of Medicine, One Baylor Plaza, Houston, TX 77030).

COMMENT. Different MECP2 mutations have similar Rett syndrome phenotypic consequences, and random $\mathrm{X}$ chromosome inactivation plays a role in the full phenotypic spectrum of classic RTT.

Amino acid receptors in frontal cortex in RTT syndrome. A study at Johns Hopkins University, Kennedy Krieger Institute, showed that the densities of $\mathrm{N}$-methyl-D-aspartate, AMPA, and GABA, measured autoradiographically in the superior frontal gyrus, were higher in younger patients and lower in older patients when compared with controls. The age-related changes in amino acid receptor density could be correlated with the stages of RTT syndrome, younger age-stage II/III regression and seizures to a less epileptic plateau stage in older girls. (Blue ME, Naidu S, Johnston MV. Development of amino acid receptors in frontal cortex from girls with Rett syndrome. Ann Neurol 1999;45:541-545).

\section{ATTENTION DEFICIT DISORDERS}

\section{DAMP DIAGNOSIS}

A simplified pediatric school entry screening examination for the syndrome of deficits in attention, motor control and perception (DAMP) is suggested from the Goteborg University, Sweden. A population-based cohort of 113 children, 6-7 years of age (62 with and 51 without DAMP), were compared on measures of attention, motor function, language, and cognition. Attention deficits were identified by both parents and pediatrician. Four of nine motor function tests and visual reaction times discriminated between the DAMP and control groups. Design copying for diagnosing perceptual disorders was better than block design and object assembly WISC subtests. Full-scale WISC IQs were lower in the DAMP group, and children with DAMP had greater phonological processing difficulties. (Landgren M, Kjellman B, Gillberg C. Deficits in attention, motor control and perception (DAMP): a simplified school entry examination. Acta Paediatr March 2000;89:302-309). (Respond: Christopher Gillberg MD, Department of Child 
and Adolescent Psychiatry, Goteborg University, Annedals Clinics, S-413 45 Goteborg, Sweden).

COMMENT. A simplified school entry examination involving four motor tests (standing on one foot, Fog test for associated movements, design copying and diadochokinesis), combined with clinical observation and parent interview, identified $80 \%$ of children with DAMP. In Scandinavia, DAMP replaced MBD in the 1980 s, and overlaps with ADHD. One third of children with DAMP meet criteria for $\mathrm{ADHD}$, and the remainder have ADD. Diagnosis of DAMP requires the presence of both attentional and motor/perceptual difficulties and a normal IQ Testing by a neuropsychologist is recommended in suspected cases. The inclusion of neuromotor and perceptual criteria in the diagnosis of ADHD would add some objective data to the subjective behavioral criteria of the DSM-IV diagnosis.

DAMP and MBD versus $\mathrm{AD} / \mathrm{HD}$ and hyperkinetic disorders is discussed in an invited commentary from the Children's Hospital. Karolinska Hospital, Stockholm, Sweden (Rydelius P-A. Acta Paediatr March 2000;89:266-268). The author refers to Rutter's publications $(1970,1994)$, stating that "brain disease with localizing neurologic signs is uncommon in children with ADDH....by contrast, the more severe hyperkinetic disorder is disproportionately common in children with damaged brains." In Sweden, "the concept of DAMP is in need of revision," as are the diagnostic criteria for ADHD in the USA.

\section{ANTIEPILEPTIC DRUGS}

\section{VIGABATRIN-ASSOCIATED "ACUTE ENCEPHALOPATHY"}

A 6-month-old girl with Alexander disease and hydrocephalus, treated at Children's Hospital, Tubingen, Germany, developed acute encephalopathy within 3 days of starting vigabatrin (VGB). She had been admitted because of seizures refractory to phenobarbital (plasma level $20 \mathrm{mg} / \mathrm{L}$ ). VGB was added in an initial dose of $150 \mathrm{mg}$ daily, and doubled the following day ( $45 \mathrm{mg} / \mathrm{kg}$ body weight). On the third day, the child became somnolent and soporous. Levels of phenobarbital were unchanged. A pre-VGB EEG showing $5 \mathrm{HZ}$ background activity changed to generalized high voltage delta waves. Causes other than VGB, including shunt dysfunction, encephalitis, metabolic disorder and renal failure, were excluded. VGB was discontinued and symptoms subsided within two days. The EEG returned to the pre-VGB $5 \mathrm{HZ}$ background activity. (Haas-Lude K, Wolff M, Riethmuller J, Niemarn G, Krageloh-Mann I. Acute encephalopathy associated with vigabatrin in a six-month-old girl. Epilepsia May 2000;41:628-630). (Reprints: Dr K Haas-Lude, Children's Hospital, University of Tubingen, Hoppe-Seyler-Strassee 1, D-72076 Tubingen, Germany).

COMMENT. Acute encephalopathy associated with VGB monotherapy has been reported in 7 adults and a child aged 14 years, but not previously in an infant. The infant was profoundly sleepy (soporous), not stuporous, and perhaps the diagnosis of "encephalopathy" could be revised to "VGB-associated excessive somnolence." A previous case of an infant with VGB-induced somnolence, necessitating drug withdrawal, was reported by Dimova PS, Korinthenberg $\mathrm{R}$ (Pediatr Neurol 1999;21:802-807). In this report, the initial dose of VGB was 5 to 63 $\mathrm{mg} / \mathrm{kg}$, increasing to 15 to $180 \mathrm{mg} / \mathrm{kg}$ (median 63). A smaller initial dose of VGB in the above case may have averted the adverse effect and the need to discontinue therapy. A similar phenomenon was common with primidone, when this antiepileptic drug was first introduced. 